\section{Treatment of main coronary obstruction with renal stent implantation after transcatheter aortic valve implantation}

\author{
Şakir Arslan (D), Nermin Bayar (D), Şükriye Uslu (D) \\ Department of Cardiology, Antalya Training and Research Hospital; Antalya-Turkey
}

\section{Introduction}

Transcatheter aortic valve implantation (TAVI) is less invasive than surgical valve replacement, but its complications can be fatal. Herein, we report a case that was successfully treated with renal stent implantation necessitated by coronary obstruction (CO) occurring during TAVI. According to our English literature search, this is the first case in which renal stent implantation has been done as a treatment for $\mathrm{CO}$ occurring during TAVI.

\section{Case Report}

An 83-year-old male patient presented to the hospital with symptoms of heart failure (New York Heart Association class III). Echocardiography showed severe aortic stenosis (mean gradient, $59 \mathrm{~mm} \mathrm{Hg}$; estimated valve area, $0.8 \mathrm{~cm} 2)$. The patient's Society of Thoracic Surgeons risk score was 4.2; he was evaluated by s, and a TAVI was scheduled.

In contrast-enhanced computed tomography (CT), the aortic annulus area and perimeter measurements were $508 \mathrm{~mm} 2$ and $81 \mathrm{~mm}$, respectively. A detailed CT image reconstruction showed left coronary ostium height, left leaflet length, sinus curvature length, and sinus of Valsalva diameter as $14.4 \mathrm{~mm}, 15.4 \mathrm{~mm}, 15.1$ $\mathrm{mm}$, and $34 \mathrm{~mm}$, respectively. Bulky calcifications, more pronounced in the left aortic leaflet, were observed (Fig. 1a-1c).

Predilatation was performed for the aortic valve using a 23 $\mathrm{mm}$ Mammoth OTW Balloon (Meril Life Sciences, India)
Calcification in the left leaflet was observed to shift toward the left main coronary artery (LMCA) when the balloon swelled, partially blocking the coronary artery. Because of a risk of $\mathrm{CO}$ after valve placement, a $5 \times 20 \mathrm{~mm}$ Simpass NC-HP balloon was inserted in the left anterior descending (LAD) artery, and then the guiding catheter was retracted into the aorta. Then a $26 \mathrm{~mm}$ balloon-expandable Myval aortic bioprosthesis was successfully implanted. After the procedure, central/paravalvular aortic regurtation was not detected in the aortography, but calcification in the valve was observed to pressure causing $70 \%$ stenosis at the LMCA (Video 1; Fig. 2a). After that, the LMCA was dilated with the balloon inserted in LAD. Even after repeated balloon deployment, sufficient dilatation was not achieved due to recoil. Thereupon, a $6.0 \times 18 \mathrm{~mm}$ RX Herculink Elite renal stent, better suited for the radial force, was implanted in the LMCA (Video 2; Fig. 2b). In control angiography, the LMCA pressure disappeared (Fig. 2c). The procedure finished without complications.

\section{Discussion}

$\mathrm{CO}$, a serious complication following $\mathrm{TAVI}$, is a rare $(1 \%)$ but fatal complication (1). Low-settled coronary ostium $(<12 \mathrm{~mm})$, a narrow sinus of Valsalva $(<30 \mathrm{~mm})$, severe valve calcification (i.e., large calcium nodules in leaflets), and a leaflet length exceeding the height of the coronary ostium are the predictive factors of $\mathrm{CO}(2-4)$.

In a study by Ribeiro et al. (3), mortality rates in patients who developed acute CO following TAVI were $22 \%$ in successful percutaneous coronary intervention (PCI), $55 \%$ in coronary artery bypass surgery, and $100 \%$ in unsuccessful PCl. For this reason, the first treatment strategy for coronary revascularization should be $\mathrm{PCl}$ and should be scheduled quickly. It has been shown that TAVI, with coronary protection in these patients, reduces the frequency and duration of cardiogenic shock (5). We kept the LMCA access open by deploying the balloon in the $L A D$ artery before valve implantation because the length of the leaflet was equal to the height of the coronary ostium; there was bulky calcification in the left leaflet, which caused pressure on the LMCA during predilatation.
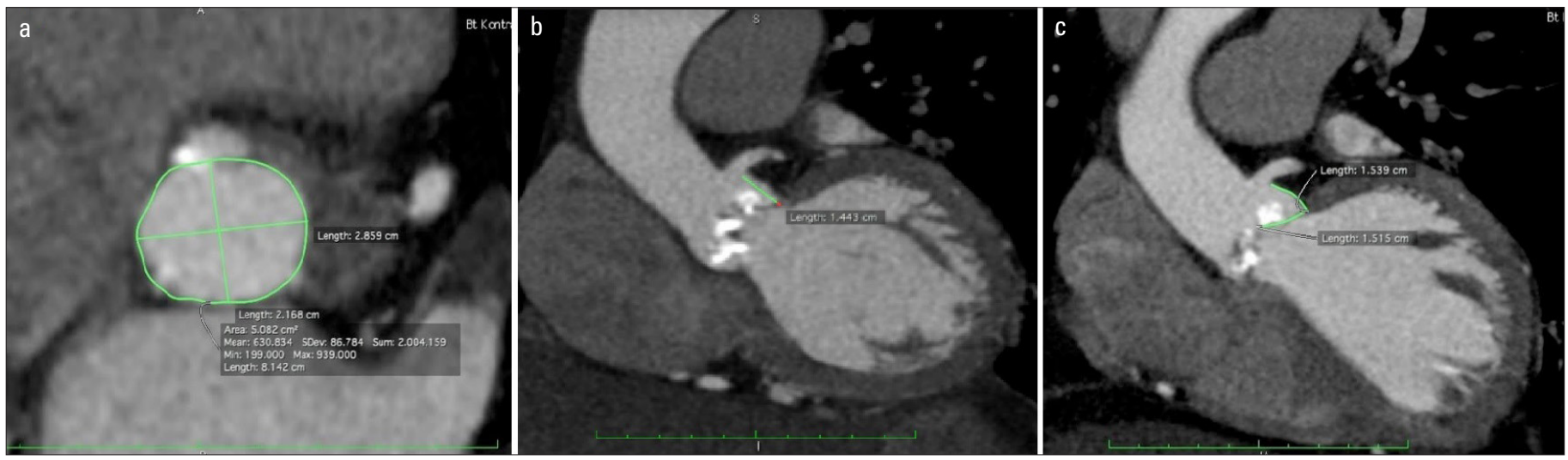

Figure 1. Multidetector computed tomography-derived aortic annulus reconstructions (a) Annular area, 508 mm²; annular perimeter, $81 \mathrm{~mm}$. (b) Left coronary artery ostium height, $14.4 \mathrm{~mm}$. (c) Left leaflet length, $15.4 \mathrm{~mm}$; sinus curvature length, $15.1 \mathrm{~mm}$ 


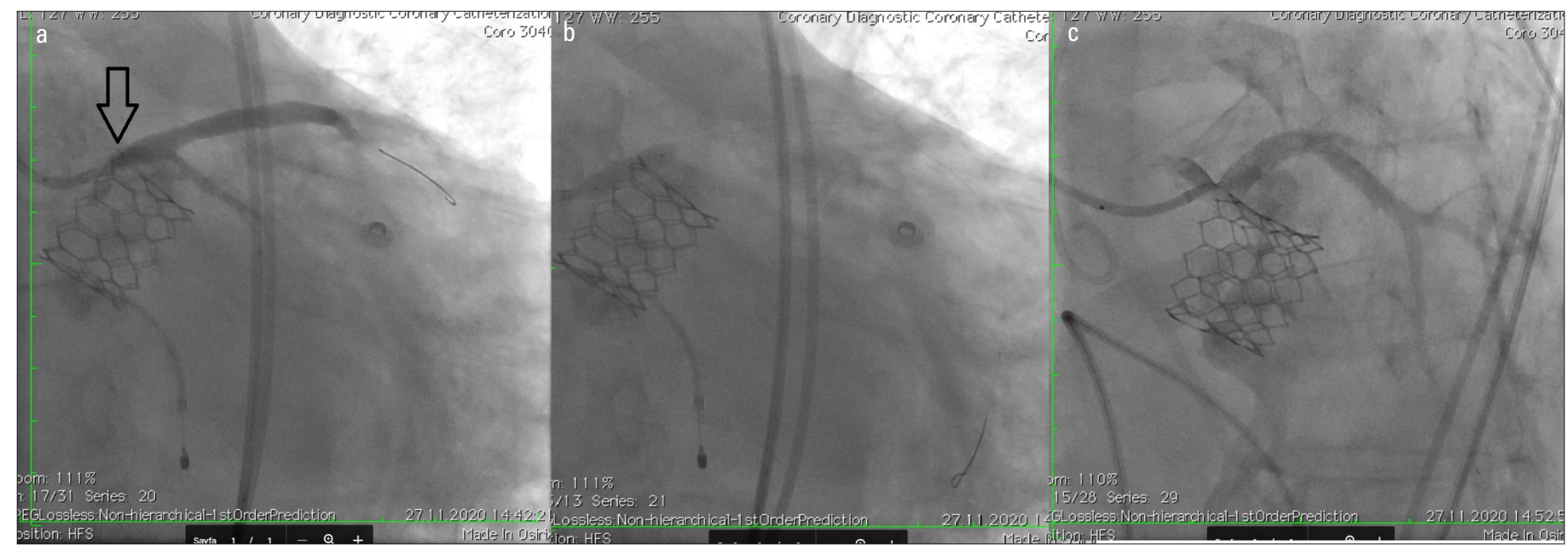

Figure 2. (a) After bioprosthesis valve implantation, calcification in the valve is observed to be applying pressure (70\% stenosis) to the left main coronary artery (LMCA). (b) The $6.0 \times 18 \mathrm{~mm}$ RX Herculink Elite peripheral stent is implanted in LMCA. (c) LMCA pressure is observed to disappear

In the literature, for patients who develop CO, stent placement after predilatation using non-compliant (NC) balloons and then dilating the stent at high pressure with NC balloons is the most commonly performed procedure. However, a second stent may be needed due to early/late recoil of the inserted stent (6-9). In the case report of Çakal et al. (6) although they first treated the LMCA with a drug-eluting stent and then a bare-metal stent, they reported that leaflet calcification-based stent compression persisted, and stent implantation was performed for these two stents to obtain a better radial force. In our case, it was predicted that leaflet calcification could cause stent compression; so stent compression was prevented, and optimal coronary revascularization was achieved by performing renal stent implantation with a better radial force to the coronary stent.

Using renal stents with better radial force to prevent stent compression should be considered as a practical, rational, and reliable method for optimal revascularization.

Informed consent: Informed consent was obtained from the patient.

Video 1. Calcification of the valve applying pressure to the left main coronary artery ( $70 \%$ stenosis) after bioprosthesis valve implantation

Video 2. The $6.0 \times 18 \mathrm{~mm} \mathrm{RX}$ Herculink Elite peripheral stent is implanted in the left main coronary artery

\section{References}

1. Arai $T$, Lefèvre $T$, Hovasse $T$, Garot $P$, Benamer $H$, Unterseeh $T$, et al. Incidence and predictors of coronary obstruction following transcatheter aortic valve implantation in the real world. Catheter Cardiovasc Interv 2017; 90: 1192-7. [Crossref]

2. Ribeiro HB, Nombela-Franco L, Urena M, Mok M, Pasian S, Doyle $D$, et al. Coronary obstruction following transcatheter aortic valve implantation: a systematic review. JACC Cardiovasc Interv 2013; 6: 452-61. [Crossref]
3. Ribeiro HB, Webb JG, Makkar RR, Cohen MG, Kapadia SR, Kodali S, et al. Predictive factors, management, and clinical outcomes of coronary obstruction following transcatheter aortic valve implantation: insights from a large multicenter registry. J Am Coll Cardiol 2013; 62: 1552-62. [Crossref]

4. Okuyama K, Jilaihawi $H$, Makkar RR. Leaflet length and left main coronary artery occlusion following transcatheter aortic valve replacement. Catheter Cardiovasc Interv 2013; 82: E754-9. [Crossref]

5. Yamamoto M, Shimura T, Kano S, Kagase A, Kodama A, Koyama Y, et al. Impact of preparatory coronary protection in patients at high anatomical risk of acute coronary obstruction during transcatheter aortic valve implantation. Int J Cardiol 2016; 217: 58-63. [Crossref]

6. Çakal B, Çakal S, Karaca 0, Boztosun B. Acute left main coronary artery occlusion following transcatheter aortic valve replacement without obvious risk factors of coronary obstruction. Anatol $\mathrm{J}$ Cardiol 2020; 23: 302-4. [Crossref]

7. Spina R, Khalique 0, George I, Nazif T. Acute left main stem coronary occlusion following transcatheter aortic valve replacement in a patient without recognized coronary obstruction risk factors: a case report. Eur Heart J Case Rep 2018; 2: yty112. [Crossref]

8. Saia F, Marrozzini C, Marzocchi A. Displacement of calcium nodules of the native valve as a possible cause of left main occlusion following transcatheter aortic valve implantation. J Invasive Cardiol 2011; 23: E106-9.

9. Ito M, Tada N, Ootomo T, Inoue N. A case of double stent implantation for left main coronary artery occlusion in transcatheter aortic valve implantation using SAPIEN XT device. Cardiovasc Interv Ther 2017; 32: 445-50. [Crossref]

Address for Correspondence: Dr. Şükriye Uslu,

Antalya Eğitim ve Araştırma Hastanesi,

Kardiyoloji Kliniği, Antalya-Türkiye

Phone: +90 2422494400

E-mail: sukriyeuslu@gmail.com

(C) Copyright 2021 by Turkish Society of Cardiology -

Available online at www.anatoljcardiol.com

DOI:10.5152/AnatolJCardiol.2021.44373 